\title{
Bone loss and fractures in multiple sclerosis: focus on epidemiologic and physiopathological features
}

REVIEW

\section{Yannis Dionyssiotis}

Rehabilitation Department, Physical and Social Rehabilitation Center, Amyntæo, Florina, Greece
Correspondence: Yannis Dionyssiotis Physical and Social Rehabilitation Center Amyntæo, Amyntæo, 53200 , Florina, Greece $\mathrm{Tel}+3023863503$ I 2

Mob +306946469759

Fax +302386020238

Email yannis_dionyssiotis@hotmail.com
This article was published in the following Dove Press journal:

International Journal of General Medicine

2 July 2011

Number of times this article has been viewed

\begin{abstract}
Multiple sclerosis (MS) affects the central nervous system leading to disability and is complicated by bone loss and fractures. Despite the acceptance of osteoporosis and fractures as two major public health problems, in people with MS the mechanisms have not been investigated adequately. Physicians and patients usually focus on the major cause of disability and neglect the multiple risk factors for osteoporosis and fractures in this specific population. This review updates the epidemiology and physiopathological mechanisms in MS.
\end{abstract}

Keywords: multiple sclerosis, bone, fractures, osteoporosis, osteopenia

\section{Introduction}

Multiple sclerosis (MS) is a chronic inflammatory disease affecting the brain and spinal cord $^{1}$ leading to muscle weakness, coordination and balance problems, as well as sensation disorders, visual and cognitive deficits, and gradual limitation of functioning. ${ }^{2}$ Subjects with MS have multiple risk factors for osteoporosis, a disease characterized by low bone mass and destruction of the microarchitecture of bone tissue, resulting in increased bone fragility and susceptibility to fractures. ${ }^{3}$ In this pathological lesion of the brain and spinal cord there are differences according to the evolution or not of the lesion (ie, progressive MS vs relapsing remitting), residual mobility and functionality, the ability to walk and stand and drug treatment (ie, corticosteroid therapy, interferon therapy). In addition there are differences in the degree of spasticity experienced by MS subjects, a complication caused by alterations in the nerve impulses to the muscles resulting in spasms and stiffness. Disturbed coordination and balance in these subjects cause frequent falls. ${ }^{2}$ The element of fatigue and muscle weakness in disabilities such as MS needs to be taken into account because it reduces the mobility of these patients significantly. ${ }^{4}$ It is also obvious that patients with this disorder often face depression leading to difficulties in complying with the proposed treatments by physicians and limiting mobility. ${ }^{5}$

In relation to osteoporosis and fractures, the role of factors that do not change, such as race or gender of patients, has not been yet clarified, although a few studies in women have argued that bone mass in women with disabilities is more affected than men. ${ }^{6}$ Women with disabilities have a higher risk of osteoporosis than men because of the inevitable reduction in estrogen levels that occurs at menopause. Although there are several studies of bone mass in women with MS, higher rates of osteopenia and osteoporosis have been reported in women with spina bifida or spinal cord injury with lower T-scores than women with other types of disability. The finding that 
women with serious disabilities have low bone density is not surprising and is probably related to the lack of activity (reduced mobility, reduced loading on bone) and worsening of the disability. ${ }^{7}$

\section{Epidemiology of osteopenia, osteoporosis, and fractures in MS}

In a relatively young (mean age: $51.29 \pm 8.7$ years) male MS population, $80 \%$ of cases could be defined as osteopenia or osteoporosis. ${ }^{8}$ A study using North American Research Committee on Multiple Sclerosis (NARCOMS) Registry data reported that more than $25 \%$ of participants had low bone mass, while $15 \%$ of subjects had a history of fracture after age 13 years. Among those reporting fractures $46.2 \%$ reported multiple fractures, $35.2 \%$ wrist fracture, $11.1 \%$ vertebral fracture, and $7.4 \%$ hip fracture. Moreover, $15.1 \%$ of participants had one clinical risk factor for fracture (except age), $25.0 \%$ had two, and $57.7 \%$ had three or more. More than $50 \%$ of fracture subjects reported taking calcium supplements, $68.8 \%$ reported taking vitamin D supplements or a multivitamin with vitamin $\mathrm{D}$, and $22.5 \%$ reported taking a bisphosphonate. ${ }^{9}$

\section{Physiopathologic mechanisms}

Physiopathology of bone loss in disabilities is multifactorial in acute and chronic phase. The main cause of osteoporosis is not well understood, ${ }^{10}$ although the problem was detected 50 years ago. ${ }^{11,12}$ Furthermore, few studies have examined the relationship between osteoporosis and/or immobilization with neurological disorders in which there is a gradual progressive or relapsing condition such as MS accompanied by bone loss. The disuse seems to play a role, ${ }^{13}$ but most believe that immobilization of these patients is a minor factor in the etiology of osteoporosis. The loss of mechanical stimuli in bone is a major challenge and has an effect on bone integrity. Reduced mobility has been implicated as an important factor in bone loss in patients suffering from MS and it seems to greatly influence bone mineral density (BMD) of the femur. ${ }^{14}$ Immobilization due to motor paralysis from lesion of the central nervous system contributes to changes, which are: (a) the lack of the normal load applied to bone in the upright position and (b) the reduced number and intensity of muscle contractions. A severe form of MS can result in a wheelchair-bound patient having a clinical outcome equivalent to paraplegia, but another MS patient may have an appropriate walking gait pattern (ie, using ankle foot orthosis) or may also be bedridden. These situations result in a variable reduction of compressive forces on bone usually performed in an up right position. Moreover, since ground reaction forces are reduced, muscle strength needed to produce movement is very low. ${ }^{15}$ Reduction of mechanical stress on bone inhibits osteoblast-mediated bone formation and accelerates osteoclast-mediated bone resorption, and leads to what has been called disuse osteoporosis. ${ }^{16}$ Grabois also reports that the primary factor for the activation of bone structure is weight bearing. Therefore, immobilization in general leads to osteoporosis from disuse, as evidenced by increased urinary calcium and reduced bone density. ${ }^{17}$ However, the high proportion of ambulatory patients with bone loss suggests additional nonmechanical factors. ${ }^{18}$

Spasticity is considered by many researchers to be a prophylactic factor for bone. It is well known that voluntary muscle contraction is effective in the prevention of osteoporosis. ${ }^{19,20}$ Muscle spasms and muscle tension in the presence of spasticity can put force on bones. This is likely to play a regulatory role in maintaining bone density. Patients without spasticity usually have more fractures. At the same time excessive spasticity may cause fractures through uncontrolled limb movements, ie, in a wheelchair. Therefore, spasticity probably has two effects on bone: a low grade of spasticity benefits, while a high spasticity grade could be detrimental. ${ }^{21,22}$ Studies in spinal cord-injured (SCI) subjects have reported controversial results for the effect of spasticity on BMD, ie, either less reduction of BMD in the spastic SCI compared with flaccid SCI subjects, or spasticity may be protective against bone loss in SCI, but without any preserving effect in the tibia. ${ }^{23}$ Only one MS study assessed the relationship between spasticity and bone strength, measured by quantitative ultrasound of cortical bone, using tibial speed of sound (SOS, $\mathrm{m} / \mathrm{second}$ ) at midpoint of the tibial shaft. Results showed preserved bone strength in MS patients and increased SOS related to spasticity in a subgroup of female patients. $^{24}$

MS patients have a high incidence of vitamin D deficiency as defined by levels of 25-hydroxy vitamin D (25-OH D) $<20 \mathrm{ng} / \mathrm{mL}$. ${ }^{25}$ The reasons might be due to a combination of low dietary vitamin $D$ intake and avoiding sun exposure, because MS symptoms may worsen after sun exposure (fatigue-related heat) leading these patients to avoid sun. There is a direct link between sunlight exposure and vitamin D3 production in the skin, which is biologically inactive but is converted by 25 -hydroxylase (25-OHase) enzyme in the liver to $25-\mathrm{OH} \mathrm{D}$, the circulating form of vitamin $\mathrm{D}$. The low intake of vitamin $\mathrm{D}$, which is supplied by food either in vitamin D2 (ergocalciferol, activated ergosterol), found in yeast, or vitamin D3 (cholecalciferol), found in fish, can be bypassed through supplements. ${ }^{26}$ 
On the other hand, we have no strong evidence to support supplementation because double-blind randomized placebo-controlled studies had insufficient power. ${ }^{27,28}$ Low testosterone alone in these populations does not explain bone loss and no clear effect of smoking or alcohol abuse on decreased bone mass could be established. ${ }^{8}$

In osteoporosis, molecular mechanisms leading to bone loss are inadequately explained. There is evidence of interaction between bone and the immune system. $T$ cell activity could stimulate bone loss under certain circumstances such as estrogen deficiency. Women with postmenopausal osteoporosis have higher $\mathrm{T}$ cell activity than healthy postmenopausal subjects, which could also be the case in inflammatory or autoimmune disorders like MS; receptor activator of nuclear factor kappa B ligand (RANKL) stimulates osteoclas to genesis as do cytokines, such as tumor necrosis factor alpha, interleukin (IL)-1, or IL-11, all produced by T cell activation, leading to bone destruction. In contrast, osteoprotegerin (OPG) is an osteoclastogenesis inhibitory factor preventing the function of RANKL. A balanced system of RANKL/ OPG regulates bone metabolism. In MS the balance of this system is shifting from OPG to RANKL. ${ }^{29,30}$

Glucocorticoid (GC)-induced osteoporosis is the main type of secondary osteoporosis. ${ }^{31-36}$ The mechanism is that excess GCs cause a rapid and significant damage to bone quality. Now we know that GCs act directly on bone mainly through the stromal/osteoblastic lineage, and at high concentrations their differentiation, survival, and function is altered, causing a shift from osteoblastic to adipocytic differentiation of precursors; inducing apoptosis of mature osteoblasts; and inhibiting synthesis and secretion of bone components. ${ }^{37,38}$ Finally, GCs promote osteoclasts and stimulate bone resorption. ${ }^{39}$ The mechanisms of GCs action in bone have been studied extensively. In patients receiving chronic oral GCs, bone loss occurs rapidly and is evident within 6 or even 3 months. ${ }^{18}$ A study investigating the effect of intravenous administration of GCs in MS patients found no clear effect on bone loss; on the contrary they reported an increase in BMD of the lumbar spine. ${ }^{40}$ Prolonged treatment with GCs results in increased risk of fractures, evident at 3 months, regardless of changes in BMD. High-dose, short-term intravenous treatment with GCs leads directly to reduction of bone formation and increased bone resorption, as indicated by markers of bone turnover. ${ }^{41,42}$ In the study by Zorzon et al, osteopenia, not osteoporosis was significantly more frequent in patients with MS than in controls, especially in women who received high-dose methylprednisolone pulses (HDMP) in relapse periods, highlighting the importance of regular monitoring of BMD in these patients. The authors concluded that disability and the subsequent immobilization that osteoporosis can result in is the more serious factor in this group and treatment with repeated HDMP pulses did not cause osteoporosis in MS subjects followed-up for almost 8 years, unlike chronic corticosteroid therapy which induces osteoporosis and/or recovery of BMD is permitted without permanent skeletal damage. ${ }^{43}$

Besides GCs, in pharmaceutical management of MS, immunomodulatory, antiepileptic and antidepressant drugs are usually used. In Japanese women with rheumatoid arthritis, methotrexate use was associated with a nonvertebral fracture risk, whereas methylenetetrahydrofolate reductase gene polymorphism status does not appear to be a clinically useful marker for predicting fracture risk. ${ }^{44}$ Moreover, researchers from St James's Hospital in Ireland provided new insights into MS therapy with evaluation of bone mass in patients with MS on immunomodulatory therapy (IMT). BMD was measured by dual energy $\mathrm{X}$-ray absorptiometry in 37 patients with MS who received different IMTs: interferon beta- $1 \mathrm{a}$ in $70 \%$, interferonbeta- $1 \mathrm{~b}$ in $27 \%$, and glatiramer in 3\% was administrated combined with high-dose pulse corticosteroid therapy (intravenous methylprednisolone $500 \mathrm{mg}$ ) in $81 \%$ ranging from 1 to 17 courses. Both mean BMD Z-score at spine of 0.53 (95\% confidence intervals [CI]: $0.15-0.92 ; P=0.0084)$ and mean BMD $Z$-score at femur of 0.72 (CI: $0.42-1.01 ; P<0.0001$ ) were significantly greater than zero, which suggested that IMT may have a favorable effect on bone in patients with MS even in the presence of pulse steroid therapy. ${ }^{36}$ The answer may lie in the molecular mechanisms regulating bone remodeling and underlying factors like induction of endogenous interferon beta (IFN-beta). The RANK-RANKL interaction induces IFN-beta and osteoclastogenesis via induction of the c-fos gene. The bond of IFN-beta to its biological receptor causes an inhibition of c-fos protein production and osteoclast proliferation and differentiation. ${ }^{45}$ Moreover, with the use of enzyme-inducing antiepileptic drugs, bone loss is accelerated by the metabolism of vitamin D3, leading to decreased calcium absorption, secondary hyperparathyroidism, greater bone resorption, and a continuous negative feedback. It has been already shown that valproate stimulates osteoclast activity. ${ }^{46}$ The discovery of functional serotonin (5-hydroxytryptamine; 5-HT) transporters (5-HTT) raised questions about the physiologic role of 5-HT in bone. 5-HT is linked to depression and 5-HTT is implicated in the physiopathology of this disease because 5-HTT antagonists are the basic drugs of antidepressant therapy. Studies support a relationship between selective serotonin reuptake inhibitors (SSRI) use and lower BMD/change 
in BMD, both in cross-sectional and longitudinal analyses. Several large studies have demonstrated either similar or increased rates of hip fracture among SSRI users compared with tricyclic antidepressant users. ${ }^{47}$

\section{Conclusion}

All MS patients should be considered high risk for osteoporosis and falls. Despite the fact that the design of studies is mostly cross-sectional, it is clear that MS induces bone loss. Prevention with calcium-rich foods, dietary supplements containing vitamin $\mathrm{D}$, and antiosteoporotic drugs is necessary for these patients. Particular attention should be paid to transfers and falls prevention in this population to prevent fractures, which occur easily and heal slowly. ${ }^{48}$ The ranking system of the World Health Organization created for postmenopausal osteoporosis focused mainly on healthy people. At the same time, despite the increased number of risk factors in people with MS there are no guidelines on BMD measurements. Future studies need to focus on this issue and also to find answers on neural control in bones.

\section{Disclosure}

No benefits in any form have been received or will be received from a commercial party related directly or indirectly to the subject of this article.

\section{References}

1. Compston A, Coles A. Multiple sclerosis. Lancet. 2008;25: 1502-1517.

2. Rietberg MB, Brooks D, Uitdehaag BMJ, Kwakkel G. Exercise therapy for multiple sclerosis. Cochrane Database Syst Rev. 2005;1: CD003980.

3. NIH Consensus Development Panel on Osteoporosis Prevention, Diagnosis, and Therapy. Osteoporosis, diagnosis, and therapy. JAMA. 2001;285:785-795.

4. Krupp LB, Serafin DJ, Christodoulou C. Multiple sclerosis-associated fatigue. Expert Rev Neurother. 2010;10:1437-1447.

5. Alajbegovic A, Loga N, Tiro N, et al. Depression in multiple sclerosis patients. Med Arh. 2011;65:115-118.

6. Smeltzer SC, Zimmerman V, Capriotti T. Osteoporosis risk and low bone mineral density in women with physical disabilities. Arch Phys Med Rehabil. 2005;86:582-586.

7. Garland DE, Adkins RH, Stewart CA, et al. Regional osteoporosis in women who have a complete spinal cord injury. J Bone Joint Surg Am. 2001;83A:1195-1200.

8. Weinstock-Guttman B, Gallagher E, Baier M, et al. Risk of bone loss in men with multiple sclerosis. Mult Scler. 2004;10:170-175.

9. Marrie RA, Cutter G, Tyry T, et al. A cross-sectional study of bone health in multiple sclerosis. Neurology. 2009;73:1394-1398.

10. Wilmet E, Ismail AA, Heilporn A, et al. Longitudinal study of bone mineral content and of soft tissue composition after spinal cord injury. Paraplegia. 1995;33:674-677.

11. Chantraine A. Actual concept of osteoporosis in paraplegia. Paraplegia. 1978;16:51-58.

12. Elias AN, Gwinup G. Immobilization osteoporosis in paraplegia. $J A m$ Paraplegia Soc. 1992;15:163-170.
13. Uebelhart D, Demiaux-Domenech B, Roth M, et al. Bone metabolism in spinal cord injured individuals and in others who have prolonged immobilisation. a review. Paraplegia. 1995;33:669-673.

14. Tüzün S, Altintaş A, Karacan I, et al. Bone status in multiple sclerosis: beyond corticosteroids. Mult Scler. 2003;9:600-604.

15. Bloomfield SA. Changes in musculoskeletal structure and function with prolonged bed rest. Med Sci Sports Exerc. 1997;29:197-206.

16. Takata S, Yasui N. Disuse osteoporosis. J Med Invest. 2001;48: $147-128556$.

17. Grabois M, ed. Physical Medicine and Rehabilitation: the Complete Approach. Malden, MA: Blackwell Science, Inc, 2000.

18. Cosman F, Nieves J, Komar L, et al. Fracture history and bone loss in patients with MS. Neurology. 1998;51:1161-1165.

19. Engelke K, Kemmler W, Lauber D, et al. Exercise maintains bone density at spine and hip EFOPS: a 3-year longitudinal study in early postmenopausal women. Osteoporos Int. 2006;17:133-142.

20. Kraemer WJ. Endocrine responses and adaptations to strength training. Strength and Power in Sport. In: Komi PV, editor. Oxford: Blackwell Scientific Publications; 1992:291-304.

21. Panin N, Gorday WJ, Paul BJ. Osteoporosis in hemiplegia. Stroke. 1971;2:41-47.

22. Ramnemark A, Nyberg L, Lorentzon R, et al. Hemiosteoporosis after severe stroke, independent of changes in body composition and weight. Stroke. 1999;30:755-760.

23. Dionyssiotis Y, Lyritis GP, Mavrogenis AF, et al. Factors influencing bone loss in paraplegia. Hippokratia. 2011;15:54-59.

24. Achiron A, Edelstein S, Ziev-Ner Y, et al. Bone strength in multiple sclerosis: cortical midtibial speed-of-sound assessment. Mult Scler. 2004;10:488-493.

25. Nieves J, Cosman F, Herbert J, et al. High prevalence of vitamin D deficiency and reduced bone mass in multiple sclerosis. Neurology. 1994;44:1687-1692.

26. Van Amerongen BM, Dijkstra CD, Lips P, et al. Multiple sclerosis and vitamin D: an update. Eur J Clin Nutr. 2004;58:1095-1109.

27. Mahon BD, Gordon SA, Cruz J, Cosman F, Cantorna MT. Cytokine profile in patients with multiple sclerosis following vitamin D supplementation. J Neuroimmunol. 2003;134:128-132.

28. Goldberg P, Fleming MC, Picard EH. Multiple sclerosis: decreased relapse rate through dietary supplementation with calcium, magnesium and vitamin D. Med Hypotheses. 1986;21:193-200.

29. Zhao W, Liu Y, Cahill CM, et al. The role of T cells in osteoporosis, an update. Int J Clin Exp Pathol. 2009;20:544-552.

30. Kurban S, Akpinar Z, Mehmetoglu I. Receptor activator of nuclear factor kappaB ligand (RANKL) and osteoprotegerin levels in multiple sclerosis. Mult Scler. 2008;14:431-432.

31. Canalis E, Bilezikian JP, Angeli A, et al. Perspectives on glucocorticoidinduced osteoporosis. Bone. 2004;34:593-598.

32. Canalis E, Mazziotti G, Giustina A, et al. Glucocorticoid-induced osteoporosis: pathophysiology and therapy. Osteoporos Int. 2007;18: 1319-1328.

33. Lakatos P, Nagy Z, Kiss L, et al. Prevention of corticosteroid-induced osteoporosis by alfacalcidol. Z Rheumatol. 2000;59(Suppl 1):48-52.

34. Mazziotti G, Angeli A, Bilezikian JP, et al. Glucocorticoid-induced osteoporosis: an update. Trends Endocrinol Metab. 2006;17:144-149.

35. Schwid SR, Goodman AD, Puzas JE, et al. Sporadic corticosteroid pulses and osteoporosis in multiple sclerosis. Arch Neurol. 1996;53:753-757.

36. Shuhaibar M, McKenna MJ, Au-Yeong M, et al. Favorable effect of immunomodulator therapy on bone mineral density in multiple sclerosis. Ir J Med Sci. 2009;178:43-45.

37. Manolagas SC. Corticosteroids and fractures: a close encounter of the third cell kind. J Bone Miner Res. 2000;15:1001-1005.

38. Pereira RC, Delany AM, Canalis E. Effects of cortisol and bone morphogenetic protein-2 on stromal cell differentiation: correlation with CCAAT-enhancer binding protein expression. Bone. 2002;30:685-691.

39. Weinstein RS, Chen JR, Powers CC, et al. Promotion of osteoclast survival and antagonism of bisphosphonate-induced osteoclast apoptosis by glucocorticoids. J Clin Invest. 2002;109:1041-1048. 
40. Schwid SR, Goodman AD, Puzas JE, et al. Sporadic corticosteroid pulses and osteoporosis in multiple sclerosis. Arch Neurol. 1996;53: 753-757.

41. De Vries F, Bracke M, Leufkens HG, et al. Fracture risk with intermittent high-dose oral glucocorticoid therapy. Arthritis Rheum. 2007; 56:208-214.

42. Van Staa TP, Leufkens HG, Abenhaim L, et al. Use of oral corticosteroids and risk of fractures. J Bone Miner Res. 2000;15:993-1000.

43. Zorzon M, Zivadinov R, Locatelli L, et al. Long-term effects of intravenous high dose methylprednisolone pulses on bone mineral density in patients with multiple sclerosis. Eur J Neurol. 2005;12:550-556.

44. Urano W, Furuya T, Inoue E, et al. Associations between methotrexate treatment and methylenetetrahydrofolatereductase gene polymorphisms with incident fractures in Japanese female rheumatoid arthritis patients. J Bone Miner Metab. 2009;27:574-583.
45. Abraham AK, Ramanathan M, Weinstock-Guttman B, et al. Mechanisms of interferon-beta effects on bone homeostasis. Biochem Pharmacol. 2009; 15:1757-1762.

46. Murthy J. Antiepileptic drugs and bone health: dietary calcium and vitamin D the confounding factors. Neurol India. 2010;58:175-176.

47. Haney EM, Warden SJ. Skeletal effects of serotonin (5-hydroxytryptamine) transporter inhibition: evidence from clinical studies. J Musculoskelet Neuronal Interact. 2008;8:133-145.

48. Cattaneo D, Jonsdottir J, Zocchi M, et al. Effects of balance exercises on people with multiple sclerosis: a pilot study. Clin Rehabil. 2007;21: 771-781.
International Journal of General Medicine

\section{Publish your work in this journal}

The International Journal of General Medicine is an international, peer-reviewed open-access journal that focuses on general and internal medicine, pathogenesis, epidemiology, diagnosis, monitoring and treatment protocols. The journal is characterized by the rapid reporting of reviews, original research and clinical studies across all disease areas.
Dovepress

A key focus is the elucidation of disease processes and management protocols resulting in improved outcomes for the patient. The manuscript management system is completely online and includes a very quick and fair peer-review system. Visit http://www.dovepress.com/ testimonials.php to read real quotes from published authors.

Submit your manuscript here: http://www.dovepress.com/international-journal-of-general-medicine-journal 